\title{
Cryoglobulinaemic vasculitis and glomerulonephritis associated with schistosomiasis: a case study
}

\author{
M.M. NasrAllah, ${ }^{7}$ H.H. Issa, ${ }^{2}$ A.A. Maher, ${ }^{3}$ T.A. Gheita ${ }^{4}$ and N.A. Osman ${ }^{7}$
}

\section{Introduction}

Schistosomiasis is a parasitic disease which is endemic in the subtropics, affecting almost 200 million people worldwide. Schistosomal antigens induce immunological responses which could provoke several forms of glomerular injury known as schistosomal glomerulopathy and that affect $10-15 \%$ of infected individuals. Schistosomiasis is classified according to the African Association of Nephrology (AFRAN) into 5 classes (1); Table 1 summarizes these classes, their pathology, clinical course and treatment. There is no role for immune suppression in schistosomal glomerulopathy, which is mostly an untreatable disease that may culminate in end-stage renal disease $(1-3)$. We present here a case of schistosomal glomerulopathy with several peculiar, novel features.

\section{Case report}

A 37-year-old male farmer from Upper Egypt presented to the emergency room in Kasr Al Ainy Medical School Hospitals in Cairo, Egypt in 2008. He came complaining of recurrent paroxysms of abdominal pain, bloody diarrhoea, tearing chest pain and haemoptysis. He was afebrile, his blood pressure was $180 / 110 \mathrm{mmHg}$ with intact peripheral pulses and he had a gangrenous left big toe.

Laboratory assessment revealed the following: haemoglobin $(\mathrm{Hb}) 7.4$ $\mathrm{g} / \mathrm{dL}(74 \mathrm{~g} / \mathrm{L})$, creatinine $2 \mathrm{mg} / \mathrm{dL}$ $(177 \mu \mathrm{M} / \mathrm{L})$ and albumin $2.1 \mathrm{~g} / \mathrm{dL}$ $(21 \mathrm{~g} / \mathrm{L})$. Urine analysis showed $3+$ albumin, granular casts, no ova and urine protein/creatinine ratio of 3.5 g/g. Stool examination was positive for occult blood. Liver enzymes, bilirubin, prothrombin time, lipid profile, blood sugar and electrolytes were within normal ranges. Duplex studies of the arterial tree of the lower limbs revealed no significant abnormalities. Abdominal ultrasound showed splenomegaly, dilated portal vein and hepatomegaly with periportal thickening. Echocardiography was diagnostic of dilated cardiomyopathy.

Days later, his temperature reached $39^{\circ} \mathrm{C}$ due to bacterial pneumonia. His total leukocyte count was 16000

\begin{tabular}{|c|c|c|c|}
\hline Class & Histopathology & Clinical course & Treatment \\
\hline I & Mesangial proliferation & $\begin{array}{l}\text { Subnephrotic to nephrotic } \\
\text { proteinuria }\end{array}$ & Usually resolves spontaneously \\
\hline II & $\begin{array}{l}\text { Exudative glomerulonephritis } \\
\text { with subendothelial \& } \\
\text { mesangial C3, IgG \& IgM } \\
\text { deposits }\end{array}$ & $\begin{array}{l}\text { Nephritic syndrome, acute } \\
\text { renal failure; associated with } \\
\text { Salmonella spp. co-infection }\end{array}$ & $\begin{array}{l}\text { Usually recovers after treatment of } \\
\text { Schistosoma spp. and Salmonella spp. } \\
\text { infections }\end{array}$ \\
\hline III & $\begin{array}{l}\text { Membranoproliferative } \\
\text { glomerulonephritis, } \\
\text { mesangial \& subendothelial } \pm \\
\text { subepithelial IgA }\end{array}$ & $\begin{array}{l}\text { Proteinuria \& chronic kidney } \\
\text { disease progressing to end stage }\end{array}$ & $\begin{array}{l}\text { No response to anti-schistosomal therapy } \\
\text { or immune suppression }\end{array}$ \\
\hline IV & $\begin{array}{l}\text { Focal segmental sclerosis } \pm \\
\text { proliferation \& IgA deposits }\end{array}$ & $\begin{array}{l}\text { Proteinuria \& chronic kidney } \\
\text { disease progressing to end stage }\end{array}$ & $\begin{array}{l}\text { No response to anti-schistosomal therapy } \\
\text { or immune suppression }\end{array}$ \\
\hline V & $\begin{array}{l}\text { Secondary amyloids in } \\
\text { glomeruli \& arterial walls } \pm \\
\text { mesangial proliferation }\end{array}$ & $\begin{array}{l}\text { Proteinuria \& chronic kidney } \\
\text { disease progressing to end stage }\end{array}$ & $\begin{array}{l}\text { No response to anti-schistosomal therapy } \\
\text { or immune suppression }\end{array}$ \\
\hline
\end{tabular}

${ }^{7}$ Department of Nephrology; ${ }^{4}$ Department of Rheumatology, Kasr Al Ainy School of Medicine, University of Cairo, Cairo, Egypt (Correspondence to M.M. NasrAllah:mmnasrallah@kasralainy.edu.eg). ${ }^{2}$ Department of Clinical Pathology, University of Beni Suef, Beni Suef, Egypt. ${ }^{3}$ Department of Internal Medicine, Zohoor Hospital, Port Said, Egypt.

Received: 18/08/14; accepted: 08/01/15 
/ $\mu \mathrm{L}$ with polymorphoneuclear leukocytosis and increased immature polymorphs. His fever responded promptly to empirically administered third-generation cephalosporins. One week later he experienced paroxysms of diffuse chest pain and haemoptysis as well as abdominal pain and bloody diarrhoea. Plasma D-dimer electrocardiography, cardiac enzymes and pulmonary perfusion scan were normal. Upper and lower endoscopies were normal, but a rectal mucosal snip biopsy was studded, revealing viable Schistosoma mansoni ova. He improved on antibiotics and supportive therapy. The paroxysms recurred in a stereotypic manner over the following months, but were not always accompanied by infection

Renal biopsy revealed membranoproliferative glomerulonephritis, with lobulated glomerular tufts, endocapillary proliferation, thickened basement membrane, and glomerular hyaline thrombisuggestive of cryoglobulin deposits. Immunofluorescence showed diffuse deposition of glomerular basement membrane immunoglobulin (Ig) M and complement component C3, with mesangial IgG, but negative for C4, fibrin and IgA. The patient had a high serum concentration of cryoglobulins (30\%) and very low levels of C3 $[15 \mathrm{mg} / \mathrm{dL}(0.15 \mathrm{~g} / \mathrm{L})$; laboratory reference $50-90 \mathrm{mg} / \mathrm{dL}$ ] and $\mathrm{C} 4[3.5 \mathrm{mg} / \mathrm{dL}(0.035 \mathrm{~g} / \mathrm{L})$; laboratory reference $10-40 \mathrm{mg} / \mathrm{dL}$. Antinuclear antibody and antineutrophil cytoplasmic antibody assays were negative.

We investigated the type and cause of the cryoglobulinaemia. The cryoglobulins were tested by immunofixation, which detected monoclonal IgM and polyclonal IgG with only traces of IgA (i.e. type II mixed cryoglobulinaemia) (Figure 1). Serum protein electrophoresis only showed hypoalbuminaemia, and bone marrow and splenic aspirates showed no abnormal cell clones. Serological

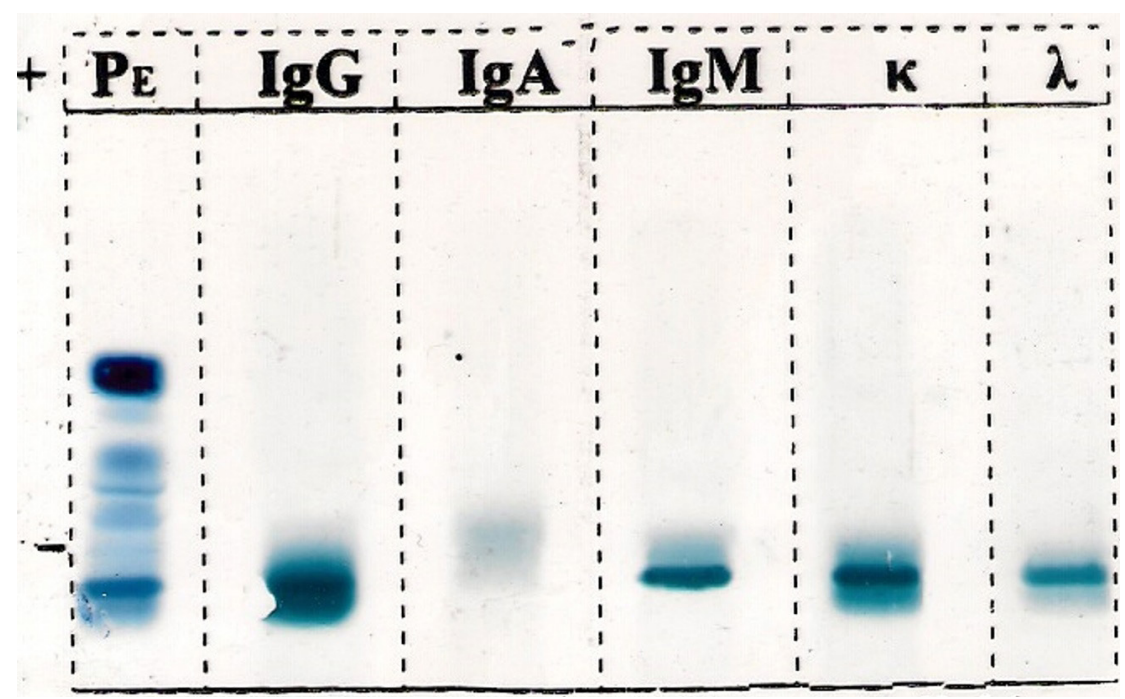

Figure 1 Serum protein electrophoresis and immunofixation of the immunoglobulin components of the cryoglobulins. The left lane shows a normal serum protein electrophoresis and the lanes to the right of it display the results of immunofixation of the cryoglobulin immunoglobulin components $(\mathrm{PE}=$ serum protein electrophoresis showing a normal pattern; IgG = broad band of IgG heavy chain denoting its polyclonal nature; $\lg M=$ narrow dense band of $\lg M$ denoting its monoclonal nature; IgA = faint band denoting minor traces of IgA heavy chains; $\kappa=$ kappa light chains; $\lambda=$ lambda light chains)

markers and nucleic acid testing for hepatitis $\mathrm{B}(\mathrm{HBV})$ and $\mathrm{C}(\mathrm{HCV})$ viruses were negative. The cryoprecipitate was isolated and found to be negative for HCV nucleic acid and antibodies. We then analysed the IgG component of the cryoglobulins and found it to be almost entirely composed of anti-adult worm antigen (AWA) Schistosoma spp. antibodies.

The patient received praziquantel, anti-platelet therapy and antihypertensive drugs, with no improvement of clinical or laboratory parameters over the following 5 months. Owing to the patient's deteriorating clinical condition, we commenced prednisolone $1 \mathrm{mg} / \mathrm{kg}$, tapered rapidly to $20 \mathrm{mg}$ and a total of 4 monthly infusions of cyclophosphamide $10 \mathrm{mg} / \mathrm{kg}$. Within 2 months, his creatinine level had dropped to $1 \mathrm{mg} / \mathrm{dL}(88 \mu \mathrm{M} / \mathrm{dL})$, urine protein/creatinine ratio to $1 \mathrm{~g} / \mathrm{g}$ and cryoglobulins to $<10 \%$. Serum albumin rose to $3.4 \mathrm{~g} / \mathrm{dL}(34 \mathrm{~g} / \mathrm{L})$ and $\mathrm{Hb}$ to $10 \mathrm{~g} / \mathrm{dL}(100 \mathrm{~g} / \mathrm{L}), \mathrm{C} 3$ and C4 levels to $38 \mathrm{mg} / \mathrm{dL}(0.38 \mathrm{~g} / \mathrm{L})$ and $10 \mathrm{mg} / \mathrm{dL}(0.1 \mathrm{~g} / \mathrm{L})$ respectively.
The paroxysms (chest and abdominal pain; haemoptysis and bloody diarrhoea) stopped and blood pressure normalized without treatment, but he continued to suffer recurrent episodes of chest infection.

He was maintained on azathioprine $100 \mathrm{mg} /$ day and prednisolone $10 \mathrm{mg} /$ day. Clinical improvement and recurrent infections prompted reduction of immunosuppression to prednisolone $5 \mathrm{mg}$ every other day and azathioprine $50 \mathrm{mg} /$ day (after 12 months of treatment).

He presented 2 months later with fever, abdominal pain, diarrhoea and rising creatinine level. Computerized tomography (CT) of chest and abdomen showed signs of pneumonia and innumerable splenic infarcts (Figure 2 ). The remaining immunosuppression was withdrawn and antibiotics were given. He passed into septic shock, with cultures that were positive for Pseudomonas aeruginosa, and he died. His family refused postmortem studies. 


\section{Discussion}

This is a report of a patient with chronic schistosomiasis associated with clinically overt features of cryoglobulinaemic vasculitis. The composition of his cryoglobulins was monoclonal IgM complexed to polyclonal IgG anti-Schistosoma spp. antibodies. By definition, this type II mixed cryoglobulinaemia is attributed to the schistosomal infection $(4,5)$.

Previous reports of cryoglobulinaemia in schistosomal disease are scarce, reporting type III cryoglobulinaemia (unlike type II reported in our patient) and lacking frank proof of presence of schistosomal antibodies in the cryoprecipitate (6-9). However, these reports were before the discovery and exclusion of HCV, a common co-infectant associated with cryoglobulinaemia. Plasma cell dyscrasia and HCV and HBV infection are well-recognized causes of cryoglobulinaemia that were excluded in our patient. Other causes of viral-induced cryoglobulinaemia, such as cytomegalovirus and Epstein-Barr virus infections, are usually transient and short-lived, coinciding with the active infection, and do not fit with the chronic clinical course of this case. The $\operatorname{IgG}$ component of the cryoglobulins was mainly composed of anti-Schistosoma AWA antibodies. Consistent evidence that schistosomiasis can induce type II cryoglobulinaemia was demonstrated in rabbits by detection of anti-schistosomal antibodies in the IgG component of cryoglobulins from rabbits infected with S. japonicum (10).

Several clinical features reported in this patient are well-recognized in small vessel vasculitis; however, manifestations of vasculitis were not reported before in cryoglobulinaemia associated with schistosomiasis. These features include non-traumatic lower extremity gangrene and ulcerations in the absence of large or medium sized arterial disease, and splenic infarcts in the absence of evidence of red-cell sickling on repeated (a)

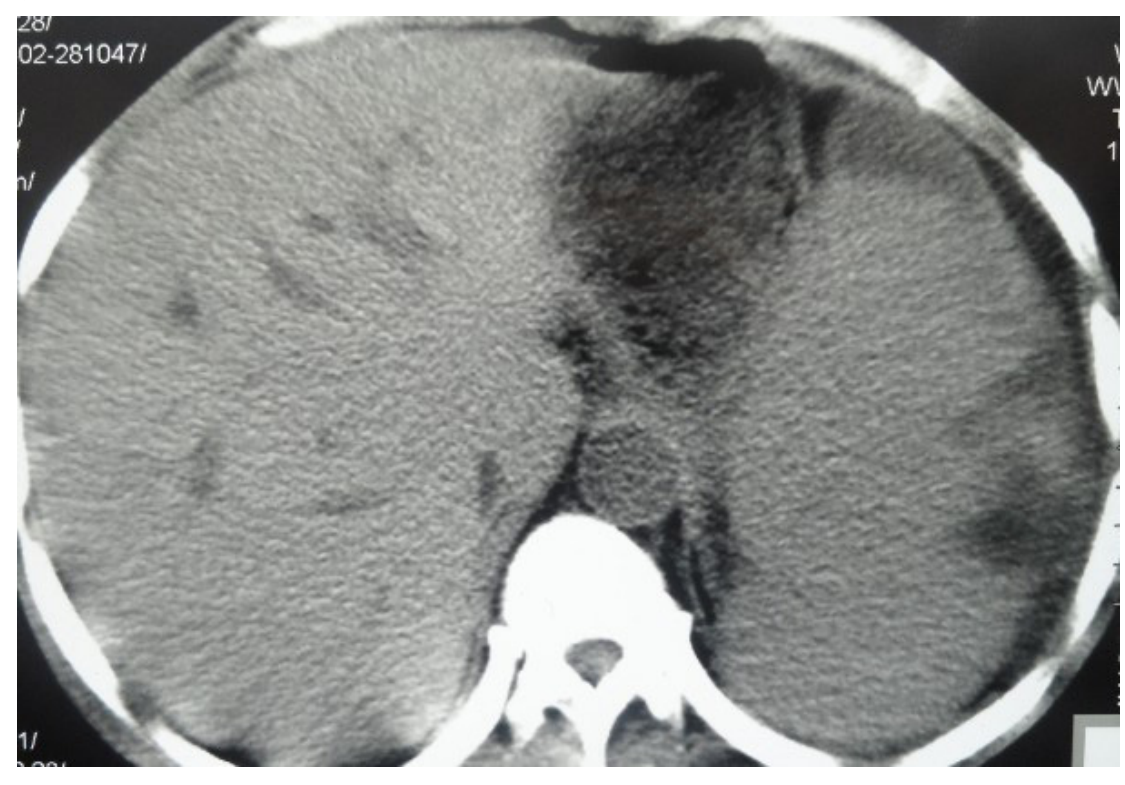

(b)

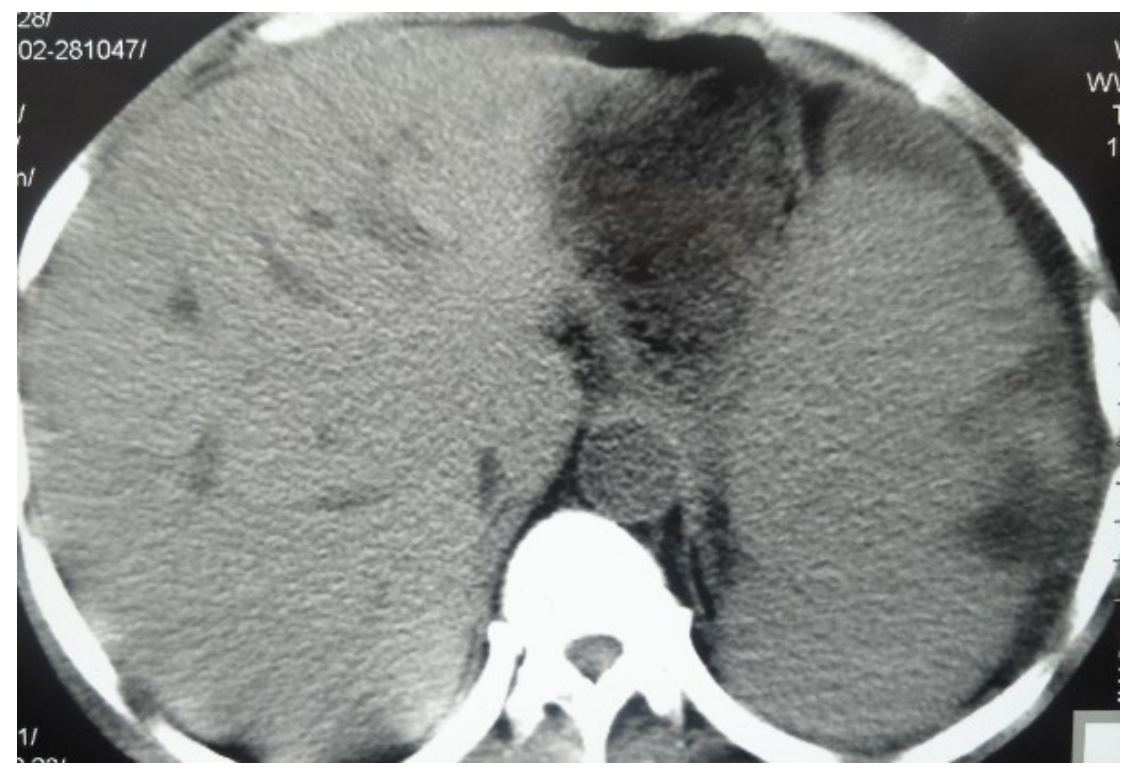

Figure 2 a/b Computerized tomography of abdomen showing multiple splenic infarcts

blood films or dilated ischaemic cardiomyopathy. The chest pain and haemoptysis in the absence of acute coronary ischemia, and the pulmonary embolism or lung pathology, suggest pulmonary vasculitis or clogging of cryoglobulins in the pulmonary vasculature. Abdominal pain and bloody diarrhoea with normal endoscopies suggest mesenteric vasculitis. Our patient suffered repeated attacks of pneumonia and viral infections even before starting immune suppression. Chronic schistosomal infection is a recognized cause of reduced antigen-specific immunity (1) and infections may have exacerbated the manifestations of vasculitis. The recurrent infections could also be explained by splenic dysfunction caused by repeated splenic infarcts. Splenic infarcts have been reported as a complication of cryoglobulinaemia (11).

There are two intriguing clinical observations in this patient. The 
first one is the absence of purpuric eruptions, a classic hallmark lesion in cryoglobulinaemia vasculitis. It is noteworthy, however, that we (9) and others (12) have reported a prevalence of this feature that is lower than previously described (5) in patients with cryoglobulinaemia vasculitis. The second bizarre feature is the very low level of $\mathrm{C} 3$, which is not common with essential cryoglobulinaemia. Again, several studies have confirmed that low $\mathrm{C} 3$ levels in cryoglobulinaemia do occur $(9,12,13)$. Moreover, the verylowlevels of $\mathrm{C} 3$ in this particular patient could be explained by the frequent presence of concomitant recurrent bacterial infections. Last but not least, this report describes a form of cryoglobulinaemia associated with anti-schistosomal antibodies which may have features different than typical $\mathrm{HCV}$-associated cryoglobulinaemia. Clinical features can vary based on the aetiology of cryoglobulinaemia (14).

Membranoproliferative glomerulonephritis with capillary hyaline thrombi together with the $\operatorname{IgG} / \mathrm{M}$ and $\mathrm{C} 3$ deposits in kidney biopsy are typical of type II cryoglobulinaemia but has not been previously described as a form of schistosomal glomerulopathy in humans. Unlike antigen/antibodyinduced schistosomal glomerulopathy, where schistosomal antigen is deposited in the glomeruli complexed to IgG (15), renal damage and vasculitis associated with cryoglobulinaemia are independent of antigen deposition $(4,5,10)$. Notably, rabbits infected with $S$. japonicum suffered cryoglobulinaemia and glomerulonephritis in the absence of schistosomal antigen deposition in the glomerular lesions (10). For these reasons we did not attempt to demonstrate schistosomal antigen in the glomeruli. Perhaps confirmation of a pathogenic effect of the detected cryoglobulins on the renal lesion may have been confirmed by elution of the antibodies in the renal biopsy to confirm their nature but this was not technically feasible.

The response of the nephritic syndrome to immune suppression may be anticipated in cryoglobulinaemia vasculitis but is not considered to be a feature of previously described cases of schistosomal glomerulopathy $(1-3,16)$. However, owing to the deterioration of the patient's condition and failure to respond to anti-schistosomal therapy, we were obliged to offer him treatment considered standard therapy for "essential" mixed cryoglobulinaemia. The response exhibited by the patient suggests that cryoglobulinaemia vasculitis associated with schistosomiasis responds to immunosuppressive therapy.

To our knowledge this is the first report explicitly revealing that antischistosomal IgG antibodies may be associated with type II cryoglobulinaemia, having the clinical features of small vessel vasculitis and glomerulonephritis and responding to immune suppressive therapy in the absence of $\mathrm{HCV}$ infection. Patients in endemic areas diagnosed with cryoglobulinaemia and/or membranoproliferative glomerulonephritis in the absence of HCV or autoimmune disease must not be simply categorized as primary membranoproliferative glomerulonephritis. Instead, schistosomal infection should be considered as a potentially treatable cause of the disease which may represent a new class of schistosomal glomerulopathy that should be sought and treated. Perhaps modification of the regimen we used or prophylaxis against bacterial infections could have modified the final outcome.

\section{Funding: None.}

Competing interests: None declared.

\section{References}

1. Barsoum RS. Schistosomal glomerulopathies. Kidney Int. 1993 Jul;44(1):1-12. PMID:8355449

2. Sobh MA, Moustafa FE, el-Housseini F, Basta MT, Deelder AM, Ghoniem MA. Schistosomal specific nephropathy leading to end-stage renal failure. Kidney Int. 1987 Apr;31(4):1006-11. PMID:3108566

3. Barsoum RS. Tropical parasitic nephropathies. Nephrol Dial Transplant. 1999;14 Suppl 3:79.

4. Foerester J. Cryoglobulins and cryoglobulinemia. In: Lee GR, Foerester J, Lukens J, Paraskevas F, Greer J, Rodgers G, editors. Wintrobe's clinical hematology. Philadelphia (PA): Williams \& Wilkins; 1999.

5. Gorevic PD, Kassab HJ, Levo Y, Kohn R, Meltzer M, Prose P, et al. Mixed cryoglobulinemia: clinical aspects and long-term follow-up of 40 patients. Am J Med. 1980 Aug;69(2):287-308. PMID:6996482

6. Agnello V, Chung RT, Kaplan LM. A role for hepatitis C virus infection in type II cryoglobulinemia. N Engl J Med. 1992 Nov 19;327(21):1490-5. PMID:1383822
7. Ferri C, Greco F, Longombardo G, Palla P, Moretti A, Marzo E, et al. Association between hepatitis $C$ virus and mixed cryoglobulinemia [see comment]. Clin Exp Rheumatol. 1991 NovDec;9(6):621-4. PMID:1662567

8. Adeiga AA, Ade-Serrano MA. Cryoglobulins in Schistosoma haematobium infection. Acta Trop. 1983 Jun;40(2):139-46. PMID:6136174

9. Gheita TA, Khairy NA, Nasrallah MM, Hussein H. Subclinical renal involvement in essential cryoglobulinemic vasculitis and classic polyarteritis nodosa. Joint Bone Spine. 2012 May;79(3):274-80. PMID:21924935

10. Robinson A, Lewert RM. Immunoglobulin M-immunoglobulin G mixed cryoglobulinemia in Schistosoma japonicuminfected rabbits. Infect Immun. 1983 Mar;39(3):1477-80. PMID:6404826

11. Giovanardi P, Mannucci C, Vandelli MR, Sansone R, Bondi M. Splenic infarcts in chronic hepatopathy accompanied by cryoglobulinemia: two case reports. Minerva Gastroenterol Dietol. 2010 Mar;56(1):81-5. PMID:20190728 
12. Cacoub P, Maisonobe T, Thibault V, Gatel A, Servan J, Musset $L$, et al. Systemic vasculitis in patients with hepatitis C. J Rheumatol. 2001 Jan;28(1):109-18. PMID:11196510

13. Cream JJ. Clinical and immunological aspects of cutaneous vasculitis. Q J Med. 1976 Apr;45(178):255-76. PMID:1085006

14. Monti G, Saccardo F, Pioltelli P, Rinaldi G. The natural history of cryoglobulinemia: symptoms at onset and during follow-up. A report by the Italian Group for the Study of
Cryoglobulinemias. Clin Exp Rheumatol. 1995 Nov-Dec;13 Suppl 13:S129-33. PMID: 8730493

15. Sobh M, Moustafa F, Ramzy R, Saad M, Deelder A, Ghoneim M. Schistosoma mansoni nephropathy in Syrian golden hamsters: effect of dose and duration of infection. Nephron. 1991;59(1):121-30. PMID:1944725

16. Barsoum R. The changing face of schistosomal glomerulopathy. Kidney Int. 2004 Dec;66(6):2472-84. PMID:15569345 